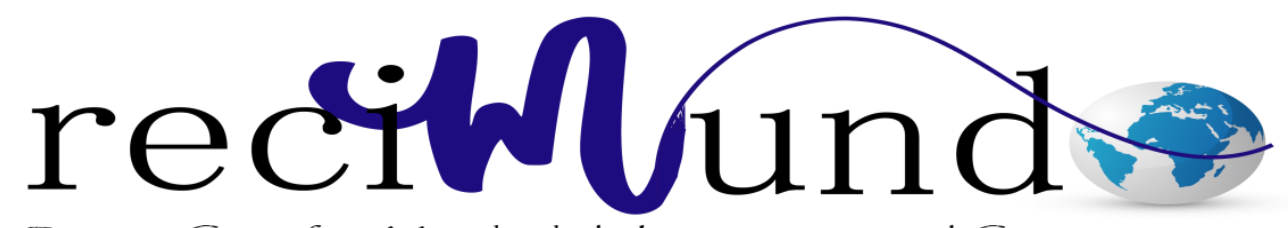

Revista Científica Mundo de la Investígación y el Conocimiento

Teresa Veliz Castro ${ }^{\mathrm{a}}$; Marcela Pincay Pilay ${ }^{\mathrm{b}}$; Carmen Baque Mendoza ${ }^{\mathrm{c}}$; Miguel Terán García $^{\text {d }}$

Las Arbovirosis, un enemigo más común de lo que se conoce

Revista Científica Mundo de la Investigación y el Conocimiento. Vol. 1 núm., 5, diciembre, 2017, pp. 680-701

DOI: 10.26820/recimundo/1.5.2017.680-701

Editorial Saberes del Conocimiento

a. Universidad Estatal del Sur de Manabí

b. Universidad Estatal del Sur de Manabí

c. Universidad Estatal del Sur de Manabí

d. Universidad Estatal del Sur de Manabí 


\section{Las Arbovirosis, un enemigo más común de lo que se conoce}

Vol. 1, núm. 5., (2017)

Teresa Veliz Castro; Marcela Pincay Pilay; Carmen Baque Mendoza; Miguel Terán García

\section{RESUMEN}

Los virus transmitidos a los seres humanos por vectores artrópodos (arbovirus) en especial por mosquitos o zancudos, han evolucionado al pasar de los años; por ello es importante estar al tanto de los cambios en su patrón epidemiológico, filogenia, capacidad de extensión, emergencia y reemergencia. Están documentados los casos de estos virus que han causado epidemias de importancia en salud pública humana en la última década, como el Dengue, Zika y Chikungunya. A partir del año 2014, se conocen casos de enfermedades que nunca habían llegado al continente americano cuyos brotes representaron situaciones de emergencia y atención por parte de las autoridades sanitarias de cada país afectado y de Organismos sanitarios internacionales, se trata de las fiebres Chikungunya y Zika. De estas tres arbovirosis, el Dengue ha tenido una mayor presencia en el continente americano. En el presente trabajo se realiza una revisión bibliográfica documental a fin de actualizar y divulgar el conocimiento sobre estos tres arbovirus que permitan recomendaciones pertinentes para estar alertas y preparados en función de la prevención y atención de estas enfermedades.

Palabras claves: Mosquito, virus, enfermedad, brotes, epidemias. 


\title{
Las Arbovirosis, un enemigo más común de lo que se conoce
}

Vol. 1, núm. 5., (2017)

Teresa Veliz Castro; Marcela Pincay Pilay; Carmen Baque Mendoza; Miguel Terán García

\begin{abstract}
Viruses transmitted to humans by arthropod vectors (arboviruses), especially by mosquitoes or mosquitoes, have evolved over the years; therefore, it is important to be aware of the changes in its epidemiological pattern, phylogeny, extension capacity, emergence and reemergence. There are documented cases of these viruses that have caused epidemics of importance in human public health in the last decade, such as Dengue, Zika and Chikungunya. As of 2014, there are known cases of diseases that had never reached the American continent whose outbreaks represented emergency situations and attention by the health authorities of each affected country and international health agencies, it is the Chikungunya and Zika fevers . Of these three arboviruses, Dengue has had a greater presence in the Americas. In the present work a documentary bibliographic review is carried out in order to update and disseminate the knowledge on these three arboviruses that allow pertinent recommendations to be alert and prepared in order to diminish the impact in terms of the prevention and attention of these diseases.
\end{abstract}

Keywords: Mosquito, virus, disease, outbreaks, epidemics. 


\section{Las Arbovirosis, un enemigo más común de lo que se conoce}

Vol. 1, núm. 5., (2017)

Teresa Veliz Castro; Marcela Pincay Pilay; Carmen Baque Mendoza; Miguel Terán García

\section{Introducción.}

Las arbovirosis son enfermedades virales transmitidas por vectores artrópodos, su nombre proviene del inglés "Arthropod-Borne Virus", que literalmente significa "virus transmitidos por artrópodos" al que se le realiza una contracción para dar origen al vocablo arbovirus, incluye un grupo de virus que pueden afectar tanto animales, incluido el humano, como a plantas. En los humanos pueden producir enfermedades muy similares como el dengue, zika, chikungunya, oropuche, fiebre amarilla, entre otras y como encefalitis, meningitis y meningoencefalitis ( Venemedia, 2014).

La Organización Panamericana de la Salud (OPS) (2016) expresa que las enfermedades causadas por arbovirus suelen presentarse en forma epidémica y son similares entre sí en su expresión clínica; constituyen un síndrome que puede ser febril y/o exantemático. Otros síntomas frecuentes son cefalea y dolores corporales, entre ellos, mialgia y manifestaciones articulares. Estas últimas pueden ser solo artralgias (como en el caso del dengue), artritis (chikungunya) o ambas (zika). También puede presentarse edema en las extremidades (chikungunya y zika) y conjuntivitis no purulenta (zika). Es importante tener en cuenta que la infección por cualquiera de estos arbovirus puede ser asintomática u oligosintomática (60 a $80 \%$, respectivamente) y pueden cursar en forma simultánea con otras infecciones, lo que dificulta aún más el diagnóstico diferencial.

El dengue es una enfermedad que data aproximadamente del siglo XVII, investigaciones sobre esta enfermedad la sitúan entre los años. 1.779 y 1.780 con casos reportados en tres

continentes (Asia, África y América). Es decir, que el común denominador es que el mosquito transportador estuvo presente en las zonas tropicales de todos los continentes, su desplazamiento 


\section{Las Arbovirosis, un enemigo más común de lo que se conoce}

Vol. 1, núm. 5., (2017)

Teresa Veliz Castro; Marcela Pincay Pilay; Carmen Baque Mendoza; Miguel Terán García

puede haber tenido su explicación en el transporte marítimo. El dengue como otras enfermedades virales ha sufrido mutaciones como el caso de una variante hemorrágica que tuvo sus primeras apariciones después de la II guerra mundial en la década de los 50 (Ramírez, A. 2013).

El dengue es una enfermedad causada por un arbovirus, del cual existen cuatro serotipos relacionados (DENV-1, DENV-2, DENV-3 y DENV-4) que afectan al humano y un quinto serotipo recientemente descubierto (DENV-5) que solo se ha evidenciado en primates no humanos. Es la virosis humana transmitida por artrópodos más constituye un problema de salud mundialmente importante. Se estima que 3.000 millones de personas viven en zonas donde hay riesgo de contraer dengue y que, aproximadamente, se dan unos 390 millones de infecciones (96 millones de ellas sintomáticas) y 20.000 muertes por dengue al año. En la Región de las Américas, el dengue representa uno de los principales motivos de consulta médica en las unidades de salud y, ante el hecho de que no hay un tratamiento específico para la enfermedad, es necesario contar con guías clínicas que permitan atender correctamente a los casos. El uso adecuado de estas pautas por personal entrenado ha reducido enormemente la tasa de letalidad por esta infección, que actualmente es de menos de 1\% (OPS, 2016).

La reciente introducción de dos nuevos arbovirus (virus Chikungunya a finales del 2013 y del virus Zika en el 2014) ha creado un nuevo desafío para la salud pública en América. Las tres arbovirosis (dengue, chikungunya y zika) pueden producir un cuadro clínico muy similar, principalmente durante la fase aguda (los primeros días de la enfermedad), dificultando así el diagnóstico clínico por parte del personal de salud y por consiguiente, creando problemas para su manejo apropiado y desencadenando en ocasiones eventos fatales. Otra dificultad planteada 


\section{Las Arbovirosis, un enemigo más común de lo que se conoce}

Vol. 1, núm. 5., (2017)

Teresa Veliz Castro; Marcela Pincay Pilay; Carmen Baque Mendoza; Miguel Terán García

ha sido a nivel del diagnóstico serológico, debido a la reacción cruzada entre los anticuerpos IgM/IgG de los virus Dengue y Zika, complicando la confirmación por laboratorio y comprometiendo de esta manera la vigilancia epidemiológica (OPS, 2016).

El ika (ZIKV) fue descrito por primera vez el bosque tropical Zika ubicado en Uganda. Las investigaciones sobre este virus sitúan su comienzo al final de la década de los años 40, cuando se empezaron a dar unos brotes de fiebre amarilla. Para su detección se escogió una zona del bosque donde interactuaban las larvas de los mosquitos (Aedes Africanus) y simios, ya que, estos se posaban sobre la corteza alta de los árboles y cuando los simios los trepaban el mosquito se transfería al cuerpo de estos. Lo que hizo que se desarrollara un proyecto del mono Rhesus. Los virus fueron inoculados en diferentes monos para generar los anticuerpos necesarios y así neutralizar el virus, algo que se logró en el año 1948 por medio del mono Rhesus 766, cuando se pudo diferenciar y detectar finalmente el virus del zika de la fiebre amarilla.

En un brote acaecido en la Polinesia Francesa en 2013 y 2014, se observó un incremento de casos de síndrome de Guillain Barre (SGB) asociados a la infección por el virus del Zika y recientemente, en las Américas, se ha asociado también a otras manifestaciones neurológicas (OPS, 2016).

En octubre de 2015, las autoridades de salud del Brasil confirmaron un aumento de la prevalencia al nacimiento de microcefalia en la región del Nordeste del país, que coincidió temporalmente con un brote por el virus del Zika. Posteriormente, se describieron otras anomalías congénitas, insuficiencia placentaria, retraso en el crecimiento fetal y muerte fetal asociadas a la infección por el virus del Zika durante el embarazo. Este último evento llevó a que el $1^{\circ}$ de febrero de 2016 la Organización Mundial de la Salud (OMS) declarase una 


\section{Las Arbovirosis, un enemigo más común de lo que se conoce}

Vol. 1, núm. 5., (2017)

Teresa Veliz Castro; Marcela Pincay Pilay; Carmen Baque Mendoza; Miguel Terán García

emergencia de salud pública de importancia internacional (ESPII) y recomendase intensificar las actividades de vigilancia e investigación sobre la relación entre los nuevos conglomerados de casos de microcefalia y otros trastornos neurológicos, incluido el síndrome de Guillain-Barré, y la infección por virus del Zika (OPS, 2016).

La Chicungunya (CHIKV) al igual que sus predecesoras es otro tipo de enfermedad viral transmitida a los humanos por la picadura de un mosquito, su origen data de los años 50, cuando su primer brote se da en Tanzania.

Las epidemias de CHIKV han mostrado históricamente una presentación cíclica, con períodos interepidémicos que oscilan entre 4 y 30 años. Desde el año 2004, el CHIKV ha expandido su distribución geográfica mundial, provocando epidemias sostenidas de magnitud sin precedentes en Asia y África. Si bien algunas zonas de Asia y África se consideran endémicas para esta enfermedad, el virus produjo brotes en muchos territorios nuevos de las islas del Océano Índico y en Italia. Esta reciente reemergencia del CHIKV ha aumentado la preocupación y el interés respecto al impacto de este virus sobre la salud pública mundial (OPS, 2011).

Aunque actualmente no hay transmisión autóctona del CHIKV en las Américas, el riesgo de que se introduzca en las poblaciones locales de mosquitos vectores es probablemente mayor de lo que se había pensado, especialmente en áreas tropicales y subtropicales donde Ae. aegypti, uno de los principales vectores del CHIKV, está ampliamente distribuido. Esta amplia distribución de vectores competentes, sumada a la falta de exposición al CHIKV de la población americana, pone a la Región en riesgo de introducción y diseminación del virus. Los grandes brotes resultantes podrían colapsar los sistemas de atención de salud existentes y la 


\section{Las Arbovirosis, un enemigo más común de lo que se conoce}

Vol. 1, núm. 5., (2017)

Teresa Veliz Castro; Marcela Pincay Pilay; Carmen Baque Mendoza; Miguel Terán García

infraestructura de salud pública, y potencialmente entorpecer algunos aspectos de la organización social (OPS, 2011).

\section{Dengue: Evolución natural de la enfermedad y signos de alarma}

El dengue es una sola enfermedad con presentaciones clínicas diferentes y a menudo, con evolución y resultados impredecibles. Se caracteriza por ser una enfermedad febril aguda en la que se observan dos o más de las siguientes manifestaciones: náuseas, vómitos, exantema, cefalea, dolor retroorbital, mialgia, artralgia, petequias o prueba del torniquete positiva y leucopenia. Este cuadro puede evolucionar y presentarse con signos de alarma tales como: dolor abdominal intenso y continuo, vómitos persistentes, acumulación de líquidos (ascitis, derrame pleural o pericárdico), sangrado de mucosas, letargo o irritabilidad, hipotensión postural, hepatomegalia mayor de dos centímetros por debajo del reborde costal, y aumento progresivo del hematocrito. La enfermedad puede también evolucionar hacia las formas más graves, con fuga plasmática, hemorragias graves o compromiso grave de órganos, pudiendo llegar a causar la muerte.

En Puerto Rico se estudió un grupo de defunciones por dengue con diagnóstico confirmado. Esos casos presentaron un conjunto de signos clínicos considerados de alarma, entre ellos: dolor abdominal intenso, vómitos persistentes, caída brusca de la temperatura y alteración del estado de conciencia; esos signos debieron poner sobre alerta a los médicos respecto de la gravedad de los pacientes. Según el estudio Dengue and control studymulticountry study o DENCO [Dengue y estudio de control-estudio en múltiples países], el dolor abdominal intenso, el sangrado de mucosas y el letargo fueron las manifestaciones clínicas 


\section{Las Arbovirosis, un enemigo más común de lo que se conoce \\ Vol. 1, núm. 5., (2017) \\ Teresa Veliz Castro; Marcela Pincay Pilay; Carmen Baque Mendoza; Miguel Terán García}

de mayor significación estadística y se presentaron 24 horas antes de que la gravedad del dengue se estableciera.

- Dolor abdominal intenso y continuo o dolor a la palpación del abdomen: El dolor abdominal intenso y continuo indica que la condición del paciente puede evolucionar o ya está evolucionando al estado de choque por dengue y sus graves complicaciones. El dolor abdominal con las características descritas no se debe a hepatomegalia de aparición más o menos brusca durante la fase crítica del dengue ni a presuntas erosiones de la mucosa gástrica. La nueva hipótesis es que el dolor intenso referido al epigastrio es un dolor reflejo determinado por la presencia súbita de una gran cantidad de líquido extravasado hacia las zonas pararrenales y perirrenales, que irrita los plexos nerviosos de la región retroperitoneal Lo anterior constituye una asociación clara entre la acumulación de líquidos en la región retroperitoneal y el choque por dengue, a la vez que indica la velocidad con que grandes volúmenes de líquidos pueden acumularse en esa región. Además, ese dolor, aunque intenso, es transitorio.

- Vómito persistente: Se define como tres o más episodios en 1 hora o cuatro episodios en 6 horas. Impiden la hidratación oral adecuada y contribuyen a la hipovolemia. El vómito persistente se ha reconocido como un signo clínico de gravedad.

- Acumulación de líquidos: Suele manifestarse por derrame pleural, ascitis o derrame pericárdico y se detecta por métodos clínicos, radiología o ultrasonido, sin que se asocie necesariamente a dificultad respiratoria ni a compromiso hemodinámico, pues de presentarse el último, se clasificaría el paciente como caso de dengue grave. 


\section{Las Arbovirosis, un enemigo más común de lo que se conoce}

Vol. 1, núm. 5., (2017)

Teresa Veliz Castro; Marcela Pincay Pilay; Carmen Baque Mendoza; Miguel Terán García

- Sangrado activo de mucosas: Suele presentarse en las encías y la nariz, pero también puede ser transvaginal (metrorragia e hipermenorrea), del aparato digestivo (vómito con estrías sanguinolentas) o del riñón (hematuria macroscópica). El sangrado de mucosas acompañado de alteración hemodinámica del paciente se considera signo de alarma para dengue grave.

- Alteración del estado de conciencia: Puede presentarse irritabilidad (inquietud) o somnolencia (letargo), con un puntaje en la escala de coma de Glasgow menor de 15 . Se acepta que ambas manifestaciones son expresión de la hipoxia cerebral provocada por la hipovolemia determinada por la extravasación de plasma.

- Hepatomegalia: El borde hepático se palpa a más de $2 \mathrm{~cm}$ por debajo del reborde costal. Puede deberse al aumento del órgano propiamente tal (por una combinación de congestión, hemorragia intrahepática y metamorfosis grasa) o por desplazamiento del hígado debido al derrame pleural y otras acumulaciones de líquido de localización intraperitoneal (ascitis) o retroperitoneal. Ha sido factor de riesgo significativo de choque en niños con dengue.

- Aumento progresivo del hematocrito: $\mathrm{Si}$ el hematocrito aumenta en al menos dos mediciones consecutivas durante el seguimiento del paciente se trata de un signo de alarma para dengue grave.

Chicungunya: Manifestaciones en la fase aguda, posaguda y crónica (OPS, 2016)

- Manifestaciones articulares: pueden presentarse artritis y artralgias inflamatorias que pueden llegar a ser intensas y producir discapacidad funcional; afectan principalmente las extremidades (muñecas, tobillos y falanges), cuadro que puede prolongarse entre dos y tres 


\section{Las Arbovirosis, un enemigo más común de lo que se conoce}

Vol. 1, núm. 5., (2017)

Teresa Veliz Castro; Marcela Pincay Pilay; Carmen Baque Mendoza; Miguel Terán García

semanas. Las manifestaciones articulares son los síntomas y signos cardinales de la enfermedad.

- Manifestaciones cutáneas: la erupción aparece entre el segundo y el quinto día después de haberse iniciado la fiebre y puede comprometer la cara, el tórax, el abdomen, las extremidades, la palma de las manos y la planta de los pies. Se puede presentar como erupción tipo eritema, exantema maculopapular morbiliforme o exantema bulloso, que luego de algunos días evoluciona a máculas hiperpigmentadas, eritema nodoso, eritema multiforme, lesiones de urticaria generalizada, reactivación de liquen plano y activación de psoriasis preexistente, prurito generalizado, descamación de la piel (síndrome de Ritter en el neonato o de Lyell en los niños mayores), necrosis nasal o de las falanges.

- Manifestaciones cardiovasculares: insuficiencia cardiaca, arritmias, miocarditis o pericarditis, angina de pecho, infarto agudo del miocardio y muerte súbita.

- Manifestaciones neurológicas: encefalitis, accidente cerebrovascular, convulsiones, meningoencefalitis, SGB (tras la fase aguda de la infección), neuropatía, mielitis, alteración mental, déficit neurológico, mieloneuropatía y parálisis flácida aguda.

- Manifestaciones oculares: visión defectuosa vinculada a neurorretinitis, coriorretinitis, neuritis óptica o uveítis.

- Manifestaciones renales: insuficiencia renal aguda prerrenal o exacerbación de un trastorno renal preexistente.

- Manifestaciones pulmonares: neumonía y neumonitis. 


\section{Las Arbovirosis, un enemigo más común de lo que se conoce}

Vol. 1, núm. 5., (2017)

Teresa Veliz Castro; Marcela Pincay Pilay; Carmen Baque Mendoza; Miguel Terán García

- Manifestaciones metabólicas: hiperglicemia y síndrome de secreción inadecuada de hormona antidiurética.

- Manifestaciones hepáticas: elevación de las transaminasas y hepatitis.

- Manifestaciones hemorrágicas: estas no son tan comunes como en la fiebre del dengue; pueden presentarse como epistaxis, sangrado de las encías, prueba de torniquete positiva, sangrado subconjuntival y erupción.

- Trastornos vasculares transitorios (por ejemplo, síndrome de Raynaud); se han informado en relación con la aparición de crioglobulinemia mixta.

En la fase posaguda (desde la cuarta semana hasta el final del tercer mes) se observan la presencia de lesiones multiformes y otras lesiones asociadas, que se caracterizan por la persistencia de manifestaciones inflamatorias iniciales que remiten lentamente, en especial: artralgia inflamatoria, artritis, sinovitis con o sin derrame, tenosinovitis o bursitis. La evolución se produce de forma continuada por brotes inflamatorios provocados con frecuencia por el frío o pueden presentarse periodos intermitentes sin síntomas. La fase posaguda puede también presentar una astenia intensa, así como el desarrollo de alteraciones neuropsicológicas, sobre todo en los casos en los que el dolor es intenso.

La fase crónica (a partir del cuarto mes) puede durar desde algunos meses hasta varios años. Se han observado las mismas manifestaciones descritas en la fase posaguda y con frecuencia la presencia de recaídas dolorosas en las articulaciones más utilizadas, dado su estado inflamatorio posterior a la infección. En síntesis, puede darse una evolución hacia la curación sin secuelas, ya sea espontánea o tras recibir tratamiento, una perseverancia prolongada de los síntomas 


\section{Las Arbovirosis, un enemigo más común de lo que se conoce}

Vol. 1, núm. 5., (2017)

Teresa Veliz Castro; Marcela Pincay Pilay; Carmen Baque Mendoza; Miguel Terán García

articulares o generales o un agravamiento conducente a un proceso inflamatorio o degenerativo.

En la mayoría de los pacientes crónicos se aprecia un empeoramiento de su calidad de vida durante los primeros años posteriores a la infección por chikungunya.

Zika: Incubación e inicio de las manifestaciones clínicas (OPS, 2016)

Se estima que el periodo de incubación promedio es de 2 a 7 días. La enfermedad tiene un inicio súbito, con exantema de tipo máculo-papular con o sin fiebre de baja intensidad (< 38,5 ${ }^{\circ} \mathrm{C}$ ). En un número significativo de los casos, la fiebre puede estar ausente. El exantema tiene una evolución céfalo-caudal (cabeza, tronco y miembros superiores e inferiores). Una característica marcada del exantema es la presencia de prurito, que muchas veces se ha descrito como impedimento a las actividades diarias del paciente e, incluso, el sueño. Con frecuencia, el exantema compromete la palma de las manos y la planta de los pies, donde constituye hiperemia palmar o plantar. En la fase de convalecencia, se podrá percibir una descamación laminar de manos y pies.

- Compromiso articular y de otros sistemas: En más de la mitad de los casos habrá compromiso articular, habitualmente en forma de poliartralgia con edema periarticular, bilateral y simétrico. En unos pocos casos el compromiso articular puede durar hasta 30 días y tener carácter recidivante en ese periodo. Las articulaciones de las manos y la muñeca son las afectadas con mayor frecuencia, seguidas de las rodillas y los tobillos.

- Compromiso del sistema nervioso: En la fase aguda podría surgir (aunque poco frecuente) encefalitis, meningoencefalitis, encefalopatía o mielitis. En general, el pronóstico es bueno, pero en algunos casos el cuadro clínico puede ser grave. 


\section{Las Arbovirosis, un enemigo más común de lo que se conoce}

Vol. 1, núm. 5., (2017)

Teresa Veliz Castro; Marcela Pincay Pilay; Carmen Baque Mendoza; Miguel Terán García

- Síndrome congénito relacionado a ZIKV: Las alteraciones del desarrollo del sistema nervioso central se caracterizaron por una amplia variabilidad en sus manifestaciones. Los casos graves presentaron microcefalia, con microencefalia e hidrocefalia. En algunos casos se ha descrito agenesia cerebelar, así como la ausencia del cuerpo calloso. Los casos más graves fueron de anencefalia. En un grupo de recién nacidos, en áreas de circulación del ZIKV, sin malformaciones macroscópicas, se observaron calcificaciones diagnosticadas por estudios de imagen. Cuando se sospecha infección congénita, es necesario realizar exámenes de laboratorio para determinar la presencia de infección congénita por citomegalovirus, herpes simplex, rubéola, VIH, toxoplamosis y sífilis. La detección de infección intraútero por ZIKV está en desarrollo, y la disponibilidad de estas pruebas es limitada. Se espera contar con pruebas serológicas que permitan mostrar la exposición previa al virus en el recién nacido y en la embarazada.

- Diagnóstico diferencial: En un paciente con exantema pruriginoso, artralgia, mialgia, edema periarticular y fiebre baja, el diagnóstico más probable sería de infección por ZIKV, siempre que las características epidemiológicas correspondientes sean compatibles. Por esa razón se impone en algunos casos realizar el diagnóstico diferencial. La infección por los virus Mayaro, Nyongnyong y otros arbovirus que causan artritis habitualmente no afectan a los habitantes de zonas urbanas, aunque habrá que estar atentos a cambios en el comportamiento epidemiológico de esos agentes.

\section{Conclusiones.}

- No existe un fármaco específico para el tratamiento de pacientes infectados con DENV, CHIKV o ZIKV. Por lo tanto, la atención clínica es sintomática, con acompañamiento 


\section{Las Arbovirosis, un enemigo más común de lo que se conoce}

Vol. 1, núm. 5., (2017)

Teresa Veliz Castro; Marcela Pincay Pilay; Carmen Baque Mendoza; Miguel Terán García

estricto (monitoreo y evaluación constante del paciente) durante la fase sintomática de la enfermedad y, en el caso del dengue, hasta dos días después de haber cedido la fiebre (OPS, 2016).

- Una revisión sistemática concluyó que no existe evidencia para apoyar o rechazar cualquier intervención evaluada para el tratamiento de enfermedades reumáticas en los pacientes con chikungunya. Se hace necesario que en un futuro se desarrollen guías de tratamiento para chikungunya informadas por la evidencia, en particular para el manejo de artritis y artralgia crónicas (OPS, 2016).

- En la actualidad no existen guías clínicas específicas para el manejo del paciente infectado por ZIKV. Por tal motivo se hace necesario el desarrollo de guías basadas en evidencia sólida para el manejo correcto de los casos. Dado que los síntomas de la infección por ZIKV son muy similares a los producidos por DENV y CHIKV (OPS, 2016).

- La infección por ZIKV es generalmente asintomática y en los casos sintomáticos su curso es autolimitado, los pacientes a menudo no necesitan tratamiento e, incluso, no buscan asistencia médica. Hasta la fecha, no existe vacuna ni tratamiento específico de la enfermedad, por lo que las medidas de atención están dirigidas al alivio de los síntomas (OPS, 2016).

- El diagnóstico de laboratorio de las arbovirosis, a diferencia de otras enfermedades víricas, no condiciona el tratamiento del paciente. La detección de marcadores de infección (detección del virus o su genoma, antígenos o anticuerpos), sustenta la confirmación del 


\section{Las Arbovirosis, un enemigo más común de lo que se conoce}

Vol. 1, núm. 5., (2017)

Teresa Veliz Castro; Marcela Pincay Pilay; Carmen Baque Mendoza; Miguel Terán García diagnóstico clínico y es de gran utilidad en la vigilancia epidemiológica de la enfermedad, pero no para el tratamiento individual (OPS, 2016).

\section{Mecanismos de prevención}

Dengue

- El médico debe elaborar la historia de la enfermedad, en la que se señalen sus principales signos y síntomas, antecedentes y la procedencia del enfermo. También se habrá de indicar si se sabe de otros casos similares en la zona de residencia del paciente (nexo epidemiológico). Simultáneamente, el médico debe realizar un examen físico completo y obtener determinados exámenes de laboratorio clínico que puedan estar disponibles en su área de consulta (OPS, 2016).

- Determinar si el paciente presenta síntomas de arbovirosis y, en caso afirmativo, el tiempo de evolución (OPS, 2016).

- Durante sus consultas posteriores, buscar signos y síntomas de alarma, los cuales preceden al choque por extravasación en los casos de dengue grave (OPS, 2016).

- Realizar un diagnóstico presuntivo y decidir su tratamiento, que puede ser ambulatorio o requerir hospitalización (OPS, 2016).

- Si se sospecha que un paciente tiene dengue, habrá que responder las siguientes preguntas: ¿En qué fase del dengue se encuentra? (febril/crítica/de recuperación), ¿Tiene signos de alarma? (dengue con signos de alarma), ¿Cuál es el estado hemodinámico y de hidratación? 


\section{Las Arbovirosis, un enemigo más común de lo que se conoce}

Vol. 1, núm. 5., (2017)

Teresa Veliz Castro; Marcela Pincay Pilay; Carmen Baque Mendoza; Miguel Terán García

¿Está en choque? (dengue grave), ¿Tiene otras afecciones concomitantes?, ¿Requiere hospitalización?

(OPS, 2016).

- Todo paciente con sospecha de dengue debe ser evaluado de manera integral. Además de evaluar la presencia o ausencia de signos de alarma o signos de gravedad, deben explorarse también otros factores o condiciones, tales como; presencia de comorbilidades (obesidad, diabetes, hipertensión, enfermedad renal, insuficiencia cardiaca), embarazo, el grupo etario (infantes y adulto mayor) y condiciones sociales (pacientes que viven solos, el acceso limitado a los servicios de salud, pobreza extrema y falta de transporte) (OPS, 2016).

\section{Chicungunya}

- Si se sospecha que un paciente tiene chikungunya, habrá que responder las siguientes preguntas: - ¿En qué fase se encuentra? (aguda/posaguda/crónica), ¿Presenta alguna manifestación no articular? ¿algún signo clínico de gravedad, formas atípicas o complicadas?, - ¿Presenta factores de riesgo de formas graves? (dolencias crónicas, edades extremas de la vida o embarazo), - ¿Cuál es el estado hemodinámico y de hidratación del paciente? (OPS, 2016).

- Reposo durante la fase febril (suspensión laboral; en caso de edema, retirar anillos y otros torniquetes, reposo relativo de las articulaciones afectadas).

- Líquidos abundantes por vía oral (prevenir deshidratación) (OPS, 2016). 


\section{Las Arbovirosis, un enemigo más común de lo que se conoce}

Vol. 1, núm. 5., (2017)

Teresa Veliz Castro; Marcela Pincay Pilay; Carmen Baque Mendoza; Miguel Terán García

- Si se cuenta con la capacidad en la unidad de salud, realizar hemograma completo (con recuento plaquetario), proteína C reactiva, velocidad de sedimentación globular (OPS, 2016).

- No se precisa realizar exámenes radiológicos de las articulaciones en esta fase (OPS, 2016).

- Referir a un hospital de segundo o tercer nivel de complejidad a aquellos pacientes con formas graves de la enfermedad (OPS, 2016).

- Tratamiento analgésico: paracetamol (nivel 1). Dosis máxima de paracetamol para adultos, 4 g al día. Niños, 10mg/kg cada 6h (OPS, 2016).

- Habrá que prestar atención especial a los pacientes con mayor riesgo de signos y síntomas poco frecuentes (personas mayores de 60 años de edad o con enfermedades crónicas, mujeres embarazadas y niños de corta edad) (OPS, 2016).

- Cuando el paracetamol resulta ineficaz., se debe combinar con Tramadol

- Determinar el estado hemodinámico del paciente e iniciar de inmediato la hidratación intravenosa en aquellos que presenten llenado capilar lento, pulso disminuido u oliguria, que son los primeros signos del choque, o signos de choque ya establecidos, hipotensión o alteración del sensorio (OPS, 2016).

- Determinar la gravedad y adoptar conductas específicas con respecto al paciente con insuficiencia renal, signos y síntomas neurológicos, insuficiencia hepática, enfermedad cardiaca, trombocitopenia, lesiones cutáneas (bulas) y afectación de otros órganos que pongan en peligro la vida del paciente o funciones importantes, como la visión (OPS, 2016). 


\section{Las Arbovirosis, un enemigo más común de lo que se conoce}

Vol. 1, núm. 5., (2017)

Teresa Veliz Castro; Marcela Pincay Pilay; Carmen Baque Mendoza; Miguel Terán García

- Iniciar el tratamiento de las complicaciones graves conjuntamente con los especialistas pertinentes. Las formas graves deben tratarse únicamente en un centro hospitalario, según las medidas convencionales de reanimación médica (OPS, 2016).

- Mujeres embarazadas: Tratamiento recomendado: paracetamol, Evitar los AINE, ácido acetil salicílico y medicamentos de uso tópico, Si la embarazada presenta infección al término del embarazo, es esencial consultar la opinión del obstetra (OPS, 2016).

- Recién nacidos y niños: No administrar AINE a lactantes menores de 3 meses de edad. No se aconseja administrar codeína a menores de 12 años de edad (excepto en casos refractarios al paracetamol, tras consulta con el especialista) (OPS, 2016).

- Fisioterapia y otras técnicas de rehabilitación: el movimiento y los ejercicios moderados tienden a mejorar la rigidez matutina y el dolor, aunque hay que tener en cuenta que el ejercicio intenso puede exacerbar los síntomas (OPS, 2016).

Zika (OPS, 2016)

- Reposo relativo mientras dure la fiebre

- Uso estricto de mosquitero durante la fase sintomática

- Uso de repelentes seguros (los que contienen DEET, IR3535 o Icaridina)

- Recomendación al paciente de que regrese de inmediato a la consulta médica, en caso de sensación de hormigueo o adormecimiento de los miembros

- Ingesta de líquidos adecuada. 


\section{Las Arbovirosis, un enemigo más común de lo que se conoce}

Vol. 1, núm. 5., (2017)

Teresa Veliz Castro; Marcela Pincay Pilay; Carmen Baque Mendoza; Miguel Terán García

- No administrar ácido acetilsalicílico a niños.

- Ante sospecha de neuritis óptica, referir al oftalmólogo para evaluación y tratamiento.

- Gotas refrescantes oculares (lágrimas artificiales).

- En casos de SGB (12): plasmaféresis (recambios de $250 \mathrm{ml} / \mathrm{kg}$ en días

alternativos) y inmunoglobulina $400 \mathrm{mg} / \mathrm{iv} / \mathrm{kg} / \mathrm{d}$ por 5 días (total $2 \mathrm{~g}$ ).

- Hidratación: recomendar la toma constante de líquidos para prevenir la deshidratación que puede ser ocasionada por pérdidas insensibles (fiebre, sudor, etc.) o por vómitos.

- Control del embarazo: a toda mujer gestante se le debe aconsejar que acuda regularmente a sus controles prenatales; también se deben cumplir los protocolos establecidos en la normativa de cada país. El control del embarazo debe llevarlo a cabo un profesional de salud capacitado (gineco-obstetra). En las consideraciones provisionales para la atención de mujeres gestantes se puede encontrar más información sobre este tema.

\section{Recomendaciones.}

A nivel gubernamental es importante el control y prevención de la proliferación de plagas.

El presente estudio, amparados en los reportes de la Organización Panamericana de la Salud muestra cuán importante es atender la Arbovirosis a tiempo pues la historia muestra, por sus características, que es una enfermedad de rápida y fácil propagación. Por tanto es de suma importancia que cada gobierno mantenga programas de información y prevención activos para evitar el contagio o desarrollo de estos virus. 


\section{Las Arbovirosis, un enemigo más común de lo que se conoce}

Vol. 1, núm. 5., (2017)

Teresa Veliz Castro; Marcela Pincay Pilay; Carmen Baque Mendoza; Miguel Terán García

Por otra parte, entendiendo que hacemos vida en espacios geográficos con características tropicales, se hace necesario mantener una dinámica de vida óptima para evitar propiciar nidos o nichos en donde se desarrollen los mosquitos, no solamente por control de plagas sino porque de ello depende que sea a misma cotidianidad quien le permita a la Arbovisoris tomar posesión de espacios y de nuestra población.

Seria interesante entrarse en un estudio que complemente el presente, considerando datos estadísticos de epidemias ocurridas y de qué manera la investigación científica aporta a la medicina para el conocimiento y control de estas enfermedades.

\section{Bibliografía.}

Gálvez Toro A. (2002). Revisión bibliográfica: usos y utilidades. Matronas profesión, (10), 25 31.

Organización Panamericana de la Salud (2016). Instrumento para el diagnóstico y la atención a pacientes con sospecha de Arbovirosis.

Organización Panamericana de la Salud (2015). Dengue guías para la atención de enfermos en la región de las Américas. Segunda edición.

Organización Panamericana de la Salud (2016). Guía para la vigilancia de la enfermedad por el virus del Zika y sus complicaciones.

Organización Panamericana de la Salud (2011). Preparación y respuesta ante la eventual introducción del virus chikungunya en las Américas

Ramírez, A. I., Torres, P., Fabro, G., Tosolini, L., \& Ferreira, M. (2013). Epidemias y salud pública.

Venemedia. (2014). Definición de arbovirus. Disponible en http://conceptodefinicion.de/arbovirus/ 